\title{
Dip Solution Dosage Form
}

National Cancer Institute

\section{Source}

National Cancer Institute. Dip Solution Dosage Form. NCI Thesaurus. Code C149435.

Liquid preparation consisting of a solution intended for veterinary use by dipping. 